\title{
Short-term outcomes of extracorporeal shock wave therapy for the treatment of chronic non-calcific tendinopathy of the supraspinatus: a double-blind, randomized, placebo-controlled trial
}

\author{
Olimpio Galasso ${ }^{1 *}$, Ernesto Amelio ${ }^{2}$, Daria Anna Riccelli ${ }^{1}$ and Giorgio Gasparini ${ }^{1}$
}

\begin{abstract}
Background: There is evidence supporting the use of extracorporeal shock wave therapy (ESWT) in calcific tendinopathy of the rotator cuff, but the best current evidence does not support its use in non-calcifying tendinopathy. We conducted a randomized placebo-controlled trial to investigate the efficacy and safety of low energy ESWT for non-calcifying tendinopathy of the rotator cuff.

Methods: 20 patients with non-calcifying supraspinatus tendinopathy (NCST) were randomized to an active or a sham treatment group. Physical, blood, roentgenographic, and MRI examinations of the shoulder were conducted to verify that patients met the inclusion and exclusion criteria. These examinations were repeated six and twelve weeks after treatments. Effectiveness was determined by comparison of the mean improvement in the Constant and Murley score (CMS) between the treatment and the placebo groups at three months. Safety was assessed by analyzing the number and severity of adverse events.
\end{abstract}

Results: All the patients completed the investigation protocol. At the final follow-up, significant improvement in the total CMS score and most of the CMS subscales was observed in the ESWT group when compared to the baseline values. Significantly higher total CMS, and significantly higher scores for CMS pain and ROM were observed in the ESWT group when compared to the placebo. No serious adverse events were noted after ESWT.

Conclusions: Patients suffering from NCST may benefit from low energy ESWT, at least in short-term. The application protocol of ESWT is likely to play a key-role in a successful treatment. Future investigations should be undertaken on the long-term effects of this technique for the treatment of NCST.

Trial registration: Current Controlled Trials ISRCTN41236511

\section{Background}

Supraspinatus tendinopathy is a common and disabling condition that becomes more prevalent after middle age $[1,2]$. There exist many forms of conservative treatment but evidence for their efficacy is not well established [3].

The shock wave is a single-impulse acoustic wave generated by an electromagnetic, electrohydraulic or piezoelectric source. The energy at the focal point is recorded in millijoules per area $\left(\mathrm{mJ} / \mathrm{mm}^{2}\right)$ and based on this value,

\footnotetext{
* Correspondence: galasso@unicz.it

'Department of Orthopaedic and Trauma Surgery, Magna Græcia University, V.le Europa88100, Catanzaro, Italy

Full list of author information is available at the end of the article
}

shock waves are classified as low, medium, or high energy [4]. In the last 20 years extracorporeal shock wave therapy (ESWT) has been widely used to treat enthesopathies $[5,6]$. Trials have examined the effect of ESWT on plantar fasciitis [7], epicondilytis [8] and jumper's knee [9]. Good evidence is available to support the use of extracorporeal shock wave therapy (ESWT) in calcific tendinopathy of the rotator cuff, but the best current evidence does not support its use in non-calcifying tendinopathy of the rotator cuff [10]. However, only a limited number of studies have reported on ESWT for non-calcifying supraspinatus tendinopathy (NCST) in the English literature [11-13]. 
We conducted a study to investigate the efficacy and safety of low energy ESWT in patients suffering from chronic NCST and compared it to placebo. Effectiveness was determined by comparison of the mean improvement in the Constant and Murley score (CMS) in the treatment and the placebo groups at three months. Roentgenographic and MRI changes of the shoulder both within and between the two groups were evaluated at follow-up. Safety was assessed by analyzing the number and severity of adverse events associated with use of the investigational treatment.

\section{Methods}

\section{Patients}

The study protocol was approved by the local Ethics Committee and the research was carried out in compliance with the Helsinki Declaration. Patients with NCST who had failed conservative treatments for a minimum of four months were evaluated for enrollment in the study. The prior regimens of conservative treatments included: administration of at least one subacromial steroid injection, one course of non-pharmacological therapy for at least 3 weeks, and one course of non-steroidal anti-inflammatory drugs or analgesics. The clinical criteria to diagnose the supraspinatus tendinopathy were a minimum six-month period of painful shoulder and pain on the Jobe [14] or full can tests [15]. The can test consists in evaluating the patient's ability to resist downward pressure on the arms held at $90^{\circ}$ elevation in the scapular plane and $45^{\circ}$ external rotation [15]. A screening interview with physical and blood examinations, an X-ray and an MRI of the shoulder were conducted to ensure that the referred patients met the inclusion and exclusion criteria (Table 1) and were willing to participate to the study. Informed consent was obtained subsequently. The blood examination consisted of a complete blood count, prothrombin time, partial thromboplastin time, and a pregnancy test for women of child-bearing potential. A general physical examination and CMS $[16,17]$ were measured by an orthopedic surgeon blinded with respect to the treatment regimen of each patient. The CMS combines subjective and objective measurements in one score. The objective parameters (65 points) include the patient's range of motion (ROM) and power, corresponding to the number of pounds of force recorded by the dynamometer. A static strength tester (CSD 300 Chatillon - Ametek Inc., U.S.A.) was used. The subjective parameters included pain and impact on activities of daily living (ADL), including positioning (35 points). The CMS increases as pain decreases and shoulder mobility increases, therefore the higher the CMS, the greater the improvement in the condition and quality of life of the patient. The CMS has been extensively validated and shows good intra- and inter-observer reproducibility [1618].

Patients were considered a treatment success if they showed an improvement of at least 30 points, or their CMS at the study's endpoint was at least $80 \%$ of the standard age- and gender-related value [11,19]. Patients observed a pain medication-free interval 3 days prior to each CMS evaluation. Baseline social, anthropometric, educational, and occupational variables that might be associated with the outcome were gathered through a study-specific questionnaire. After treatment and during follow-up, patients were restricted to the use a $1000 \mathrm{mg}$ of acetaminophen per day in cases of pain, in order to facilitate comparison of the medications and usage among the patients and groups and across all follow-up visits. The patients were randomized to an active or sham treatment group using stratified random permuted blocks with an allocation ratio of 1:1 and they were unaware whether they had received treatment. One patient initially assigned to the placebo group was lost after randomization, thus leaving twenty individuals available for the study (i.e. 11 in the ESWT and 9 in the placebo group). The study did not allow for crossover. The cohorts were scheduled at different times to ensure that the individuals within the cohorts did not contact each other.

\section{Imaging studies}

The X-ray exams consisted of anteroposterior and supraspinatus outlet views. Magnetic resonance imaging scans (Siemens Magnetom Synphony-Maestro-Class, 1,5T) were acquired for all patients and included: a fast spin-echo intermediate-weighted axial sequence, a fast spin-echo coronal oblique intermediate-weighted sequence, and coronal oblique and sagittal oblique fast spin-echo T2-weighted acquisitions with fat suppression. A supraspinatus tendinopathy was diagnosed if intermediate-weighted and T2-weighted images showed diffuse mildly increased signal intensity (not equal to that of fluid) and an intact tendon was observed [20]. A fullthickness tear was defined as a high T2 signal extending through the depth of the tendon [21]. X-rays and MRI studies were independently evaluated by two musculoskeletal radiologists, who were unaware of the clinical characteristics of the patients, and the same measurements were repeated twice on two separate days. Cohen's kappa coefficient for inter-observer and intraobserver reliability of scoring was 0.78 and 0.80 , respectively. A consensus decision on the scores was reached in a final common readout.

\section{Interventions}

The Modulith ${ }^{\circledR}$ SLK system (Storz Medical AG, Tagerwilen, Switzerland) was the electromagnetic therapy source used 
Table 1 Inclusion and exclusion criteria

\begin{tabular}{|c|c|}
\hline Inclusion Criteria & Exclusion criteria \\
\hline $\begin{array}{l}\text { 1. Male and non-pregnant female patients } 18 \text { years of age or older } \\
\text { (women of child-bearing potential must have a negative serum } \\
\text { pregnancy test performed within 1-14 days prior to the treatment } \\
\text { procedure) suffering from NCST as diagnosed by X-ray, MRI and } \\
\text { physical examination. }\end{array}$ & $\begin{array}{l}\text { 1. Patient has a history of uncontrolled severe hypertension } \\
\text { (systolic pressure }>180 \mathrm{mmHg} \text {, diastolic pressure }>110 \mathrm{mmHg} \text { ). }\end{array}$ \\
\hline $\begin{array}{l}\text { 2. Patient has not responded to a standard course of non-pharmacological } \\
\text { and non-surgical conservative treatment for a minimum of three weeks. } \\
\text { The treatment above consists of: therapeutic exercise, and/or ultrasound, } \\
\text { and/or iontophoresis, and/or cryotherapy, and/or immobilization or } \\
\text { activity modification. }\end{array}$ & $\begin{array}{l}\text { 2. Patient has unstable or uncontrolled angina, uncontrolled heart } \\
\text { failure, or serious uncontrolled ventricular arrhythmias. }\end{array}$ \\
\hline $\begin{array}{l}\text { 3. Patient has not responded to pharmacological treatment (one course } \\
\text { of the standard dose of prescribed analgesic or NSAID) and has had } \\
\text { at least one subacromial steroid injection. }\end{array}$ & $\begin{array}{l}\text { 3. Patient has a white blood cell count less than } 2,000 \text { or greater than } \\
15,000 \text {, or platelet count less than } 50,000 \text {. }\end{array}$ \\
\hline 4. Diagnosis of supraspinatus tendinopathy is only in one shoulder. & $\begin{array}{l}\text { 4. Patient has a known bleeding disorder or is currently being treated } \\
\text { with anticoagulant therapy. }\end{array}$ \\
\hline $\begin{array}{l}\text { 5. Patient has free passive range of movement and at least } 90 \text { degrees } \\
\text { active abduction in the affected shoulder. }\end{array}$ & $\begin{array}{l}\text { 5. Patient is currently being treated with a narcotic or NSAIDs and/or } \\
\text { has used analgesics or NSAIDs within the } 72 \text { hours prior to the SV. }\end{array}$ \\
\hline $\begin{array}{l}\text { 6. Patient is willing to participate in the study and return for all scheduled } \\
\text { follow-up visits. }\end{array}$ & $\begin{array}{l}\text { 6. Patient has participated in any other shoulder pain treatment } \\
\text { research study within } 30 \text { days prior to the SV. }\end{array}$ \\
\hline \multirow[t]{12}{*}{ 7. Patient is capable of giving, and has given, written informed consent. } & 7. Patient had prior shoulder surgery \\
\hline & 8. Patient received prior ESWT for any disease. \\
\hline & 9. Patient is complaining of pain in both shoulders. \\
\hline & 10. Patient has malignant tumors, irrespective of location. \\
\hline & 11. Patient has a cardiac pacemaker implant. \\
\hline & $\begin{array}{l}\text { 12. Patient has anatomy that prevents the focusing of the device into } \\
\text { the shoulder in the area of the supraspinatus tendon (e.g., extensive } \\
\text { scarring, misalignment of previous fractures, non-unions or delayed } \\
\text { fracture healing, congenital malformation, etc.). }\end{array}$ \\
\hline & $\begin{array}{l}\text { 13. Patient has any upper extremity neurological disorder as diagnosed } \\
\text { from focused neurological exam and neurophysiological studies } \\
\text { (e.g. thoracic outlet syndrome, reflex sympathetic dystrophy, etc.). }\end{array}$ \\
\hline & $\begin{array}{l}\text { 14. Patient has a full-thickness rotator cuff tear of any of the rotator cuff } \\
\text { tendons as seen on MRI. }\end{array}$ \\
\hline & $\begin{array}{l}\text { 15. Patient has an acromiohumeral interval less than } 7 \mathrm{~mm} \text { as measured } \\
\text { on a standard AP X-ray, or severe symptomatic degenerative changes in } \\
\text { the glenohumeral or acromioclavicular joint. }\end{array}$ \\
\hline & 16. Patient has acute subacromial bursitis as diagnosed by MRI \\
\hline & 17. Patient has generalized polyarthritis, rheumatoid arthritis. \\
\hline & 18. Patient is allergic to local anaesthetic. \\
\hline
\end{tabular}

SV, indicates screening visit; NCST, non-calcific supraspinatus tendinopathy; AP, Anteroposterior; NSAIDs, Non-Steroidal Anti-Inflammatory Drugs.

to treat the patients. Localization and targeting were achieved by means of an in-line $7.5 \mathrm{MHz}$ ultrasound transducer with a scanning depth range of $3-15 \mathrm{~cm}$, located in the center of the therapy source. Shock waves were focused at an area $1 \mathrm{~cm}$ proximal to the insertion of the tendon in the bone, with the patient in a supine position. The treatment regimen required administration of two treatment sessions, each consisting of 3000 shockwaves at an energy flux density of $0.068 \mathrm{~mJ} / \mathrm{mm}^{2}$, separated by a 7-day interval. A similar protocol showed to be effective in the treatment of calcific shoulder tendinopathy [22]. The sham treatment entailed use of the same device in which the shockwave generator was disconnected. A compact disc player with a prerecorded sound of the ramp-up shocks produced the sound characteristic of the device as if it had been normally activated. The speakers were stored under the upper cover of the shock wave generator. As shockwaves may cause pain and discomfort, patients in both groups received a subcutaneous injection of 2cc of $2 \%$ lidocaine above the subacromial space of the affected shoulder prior to each treatment. The patient was treated by an unblinded investigator not involved in the enrollment of the patients, their randomization, or their follow-up. The heart rate, blood pressure, body temperature, and respiration rate were measured before and immediately after each treatment. Treatments were performed as outpatient procedures.

Patients repeated the physical and blood examination and the CMS evaluation at both 6 and 12 weeks follow- 
up. At the latter follow-up the imaging studies were repeated. The use of shoulder pain medication or any other drug was recorded at the final treatment and during the follow-up period. Adverse effects were assessed by clinical examination and by a patient questionnaire directly after the ESWT/sham procedure and at every follow-up visit. An anticipated adverse device effect (Anticipated adverse event for ESWT) was considered an adverse event that had been previously identified as occurring with some frequency as a result of the device use; conversely, an unanticipated adverse device effect was one that had not been identified in its nature, severity, or frequency in the literature. Adverse events were evaluated by the investigator blinded to patient assignment. The patient's subjective opinion of the treatment received was noted at the study's conclusion. All findings were recorded on standardized forms. At the final follow-up, the patients in the control group still complaining of symptoms of supraspinatus tendinopathy were offered the real ESWT, while those in the active treatment group were informed of further options.

\section{Anticipated adverse event for ESWT}

Subcutaneous hematoma at treatment site
Petechiae at treatment site
Ecchymosis at treatment site
Increased pain in treated shoulder
Skin redness at treatment site
Bleeding
Swelling of treated shoulder
Skin irritation at treatment site
Migraine
Syncope
Nausea/Vomiting
Feeling Unwell/Dizziness

A telephone recall of the ESWT patients was carried out nine years after treatment to collect data about the number of patients who eventually progressed to surgical intervention or other treatment options. At the same time, the satisfaction with ESWT and willingness to undergo the treatment again was also recorded.

\section{Statistical analysis}

Mean, standard deviation and range were reported for the continuous variables, whereas counts described the categorical variables. Because of the low expected frequencies, a Monte Carlo method or Fisher's exact test was used for testing the significance of comparisons of the categorical variables between the ESWT group and the control subjects. An unpaired t-test was used to compare the means of quantitative variables between the groups.
Due to the non-normal distribution, non-parametric tests were used to compare the obtained shoulder ratings before and three months after starting the treatment, and between the ESWT and placebo groups. In particular, a Mann-Whitney U-test was used to assess the difference in scores distributions between the treatment and placebo groups, whereas a Wilcoxon test was used to compare the scores before and after the initiation of treatment. To calculate the power $(1-\beta$ error probability; two tailed) achieved by our statistical tests, we considered the actual sample size, the observed effect size, and the $\alpha$ value $=0.05$.

SPSS (version 17.0, SPSS Inc., Chicago, USA) and G*Power (Institut fur Experimentelle Psychologie, Heinrich Heine Universitat, Dusseldorf, Germany) software were used for the statistical analyses.

\section{Results}

All the patients completed the investigation protocol. The baseline characteristics of the study population are shown in Table 2. The demographic and all clinical data except the BMI did not differ between the ESWT group and the placebo group at baseline. No significant differences on the physical parameters were noted immediately after treatments within and between the two groups of the study. As shown in Table 3, at the earlier follow-up significant CMS changes were noted only in

Table 2 Baseline characteristics of the patients

\begin{tabular}{|c|c|c|c|}
\hline & $\begin{array}{c}\text { ESWT } \\
(n=11)\end{array}$ & $\begin{array}{l}\text { PLACEBO } \\
(n=9)\end{array}$ & $P$ value \\
\hline${ }^{*}$ Age (years) & $\begin{array}{c}50.7 \pm 8.44 \\
(38-64)\end{array}$ & $\begin{array}{c}51.11 \pm 13.26 \\
(36-74)\end{array}$ & $0.938^{\S}$ \\
\hline \multicolumn{4}{|l|}{ Sex } \\
\hline Men & 7 & 4 & $0.653^{\dagger}$ \\
\hline Women & 4 & 5 & \\
\hline${ }^{*} \mathrm{BMI}$ & $\begin{array}{c}27.4 \pm 1.04 \\
(26-29.4)\end{array}$ & $\begin{array}{c}24.4 \pm 3.15 \\
(19-29)\end{array}$ & $0.024^{\S}$ \\
\hline $\begin{array}{l}\text { *Duration of } \\
\text { symptoms (months) }\end{array}$ & $\begin{array}{c}45.36 \pm 34.33 \\
(11-131)\end{array}$ & $\begin{array}{c}61.22 \pm 24.04 \\
(34-97)\end{array}$ & $0.258^{\S}$ \\
\hline \multicolumn{4}{|l|}{ Affected side } \\
\hline Right & 7 & 6 & $0.999^{\dagger}$ \\
\hline Left & 4 & 3 & \\
\hline $\begin{array}{l}\text { Patients with } \\
\text { physiotherapy }\end{array}$ & 7 & 8 & $0.319^{\dagger}$ \\
\hline \multicolumn{4}{|l|}{ Acromion slope } \\
\hline Type I & 8 & 7 & $0.999^{\dagger}$ \\
\hline Type ॥ & 2 & 2 & \\
\hline Type III & 1 & 0 & \\
\hline \multicolumn{4}{|c|}{$\begin{array}{l}\text { *The values are given as mean } \pm \text { standard deviation (range). } \\
\text { ESWT, extracorporeal shock wave therapy; BMI, body mass index; ST, } \\
\text { supraspinatus tendon. } \\
\S \text { Unpaired t-test. } \\
{ }^{+} \text {Monte Carlo or Fisher exact test. } \\
\text { \$ann-Whitney U-test. }\end{array}$} \\
\hline
\end{tabular}


the ESWT group. The comparison between this group and the placebo group showed significant differences for the total CMS and the ROM subscale. At the final follow-up (Table 4), significant improvement in the total CMS and all the subscales (except power) was observed in the ESWT group when compared to the baseline values. In contrast, within the placebo group no statistically significant differences were observed with baseline. When the groups were compared, significantly higher total CMS and significantly higher scores for pain and ROM were observed in the ESWT group. The number and percentage of successful treatments according to the different study groups at the final follow-up are shown in Table 5. The mean relative improvement in the total CMS at three months was significantly higher in the active treatment group than in the control group $(74.5 \%$ and $15.2 \%$ respectively, $\mathrm{p}=0.014$ ).

No relevant adverse effects occurred during or after treatment, but there was a slight pain increase. Indeed, in the ESWT group, one patient reported a short-lived and bearable pain increase during the second session of

Table 3 Comparison of shoulder ratings before and 6 weeks after ESWT/sham treatment in the study or placebo groups

\begin{tabular}{|c|c|c|c|}
\hline CMS & ESWT & PLACEBO & P value ${ }^{1}$ \\
\hline \multicolumn{4}{|l|}{ PAIN } \\
\hline Baseline & $2.72 \pm 2.61(0-5)$ & $3.33 \pm 2.5(0-5)$ & 0.592 \\
\hline 6 weeks & $8.18 \pm 3.37(5-15)$ & $4.44 \pm 3.9(0-10)$ & 0.045 \\
\hline$P$ value ${ }^{2}$ & 0.006 & 0.414 & \\
\hline \multicolumn{4}{|l|}{$\mathrm{ADL}$} \\
\hline Baseline & $10.27 \pm 3.28(5-18)$ & $11.55 \pm 4.21(6-18)$ & 0.378 \\
\hline 6 weeks & $15.1 \pm 3.83(7-20)$ & $11 \pm 5.48(2-20)$ & 0.068 \\
\hline P value ${ }^{2}$ & 0.01 & 0.674 & \\
\hline \multicolumn{4}{|l|}{$\mathrm{ROM}$} \\
\hline Baseline & $16.18 \pm 4.68(10-24)$ & $16.67 \pm 8.36(2-26)$ & 0.878 \\
\hline 6 weeks & $27.27 \pm 8.5(12-40)$ & $17.1 \pm 9.06(8-32)$ & 0.038 \\
\hline P value ${ }^{2}$ & 0.006 & 0.618 & \\
\hline \multicolumn{4}{|l|}{ POWER } \\
\hline Baseline & $13.27 \pm 5.4(5-20)$ & $10.11 \pm 3.18(5-15)$ & 0.170 \\
\hline 6 weeks & $13.36 \pm 4.3(7-18)$ & $10.55 \pm 4.21(6-19)$ & 0.174 \\
\hline$P$ value ${ }^{2}$ & 0.834 & 0.726 & \\
\hline \multicolumn{4}{|l|}{ TOTAL } \\
\hline Baseline & $42.45 \pm 9.83(29-61)$ & $41.67 \pm 12.53(20-57)$ & 0.970 \\
\hline 6 weeks & $64 \pm 16.6(32-87)$ & $43.11 \pm 19.16(18-70)$ & 0.018 \\
\hline P value ${ }^{2}$ & 0.004 & 0.368 & \\
\hline
\end{tabular}

The values are given as mean \pm standard deviation (range).

${ }^{1}$ Comparison between treatment and control group both before and after treatment (Mann-Whitney U- test).

${ }^{2}$ Comparison between before and after treatment within each group (Wilcoxon test)

ESWT, indicates extracorporeal shock wave therapy; ADL, activity of daily living; ROM, range of motion; CMS, Constant and Murley Score.
Table 4 Comparison of shoulder ratings before and 3 months after ESWT/sham treatment in the study and placebo groups

\begin{tabular}{|c|c|c|c|}
\hline CMS & ESWT & PLACEBO & $P$ value ${ }^{1}$ \\
\hline \multicolumn{4}{|l|}{ PAIN } \\
\hline Baseline & $2.72 \pm 2.61(0-5)$ & $3.33 \pm 2.5(0-5)$ & 0.592 \\
\hline 3 months & $10.9 \pm 4.37(5-15)$ & $6.11 \pm 4.86(0-15)$ & 0.039 \\
\hline P value ${ }^{2}$ & 0.004 & 0.096 & \\
\hline \multicolumn{4}{|l|}{ ADL } \\
\hline Baseline & $10.27 \pm 3.28(5-18)$ & $11.55 \pm 4.21(6-18)$ & 0.378 \\
\hline 3 months & $17 \pm 4.22(8-20)$ & $12 \pm 5.63(4-20)$ & 0.059 \\
\hline$P$ value ${ }^{2}$ & 0.005 & 0.779 & \\
\hline \multicolumn{4}{|l|}{$\mathrm{ROM}$} \\
\hline Baseline & $16.18 \pm 4.68(10-24)$ & $16.67 \pm 8.36(2-26)$ & 0.878 \\
\hline 3 months & $30.9 \pm 9.05(16-40)$ & $18.22 \pm 10.50(6-36)$ & 0.012 \\
\hline P value ${ }^{2}$ & 0.005 & 0.635 & \\
\hline \multicolumn{4}{|l|}{ POWER } \\
\hline Baseline & $13.27 \pm 5.40(5-20)$ & $10.11 \pm 3.18(5-15)$ & 0.170 \\
\hline 3 months & $15.27 \pm 6(6-23)$ & $11.67 \pm 3.46(6-16)$ & 0.170 \\
\hline$P$ value ${ }^{2}$ & 0.096 & 0.119 & \\
\hline \multicolumn{4}{|l|}{ TOTAL } \\
\hline Baseline & $42.45 \pm 9.83(29-61)$ & $41.67 \pm 12.53(20-57)$ & 0.970 \\
\hline 3 months & $74.09 \pm 20.56(39-98)$ & $48 \pm 22.3(17-79)$ & 0.023 \\
\hline$P$ value ${ }^{2}$ & 0.003 & 0.260 & \\
\hline
\end{tabular}

The values are given as mean \pm standard deviation (range).

${ }^{1}$ Comparison between treatment and control group both before and after treatment (Mann-Whitney U- test).

${ }^{2}$ Comparison between before and after treatment within each group (Wilcoxon test).

ESWT, indicates extracorporeal shock wave therapy; $A D L$, activity of daily living; ROM, range of motion; CMS, Constant and Murley Score.

therapy, while two patients reported an increase in pain at final follow-up. In the placebo group an increase was noted by only one patient, at three months after treatment.

As for the medications the patients used after treatment and during follow-up, the use of acetaminophen in the ESWT and placebo group averaged 0,73 $\pm 1,68$ (range $0-5$ ) and 6,78 $\pm 13,46$ (range 0-41) days, respectively, but the difference was not statistically significant $(\mathrm{p}=0.16)$. Seven out of eleven and five out of nine patients believed they had received active treatment in the ESWT and in the placebo group, respectively. The number of patients that the blinded investigator considered as actively treated were nine in the ESWT group and two in the placebo group.

The power analyses showed that the statistical tests, used to compare the subscale of ROM and the total CMS between ESWT and placebo groups at the final follow-up, had a power respectively of $75.5 \%$ and $70.3 \%$ to detect the observed differences. The statistical tests used to compare the CMS values at follow-up and baseline within the ESWT group had a power of $99.9 \%$ for the 
Table 5 Success rate three months after shockwave therapy or sham treatment

\begin{tabular}{|c|c|c|c|c|c|c|c|}
\hline \multicolumn{4}{|l|}{ ESWT } & \multicolumn{4}{|l|}{ PLACEBO } \\
\hline PATIENT & $\begin{array}{c}\text { CMS } \\
\text { BASELINE }\end{array}$ & $\begin{array}{l}\text { CMS at } 3 \\
\text { MONTHS }\end{array}$ & $\begin{array}{l}\text { SUCCESSFUL } \\
\text { TREATMENT }\end{array}$ & PATIENT & $\begin{array}{c}\text { CMS } \\
\text { BASELINE }\end{array}$ & $\begin{array}{l}\text { CMS at } 3 \\
\text { MONTHS }\end{array}$ & $\begin{array}{l}\text { SUCCESSFUL } \\
\text { TREATMENT } \\
\end{array}$ \\
\hline 1 & 55 & 98 & Yes & 1 & 43 & 61 & no \\
\hline 2 & 31 & 39 & No & 2 & 47 & 79 & yes \\
\hline 3 & 45 & 94 & Yes & 3 & 54 & 78 & yes \\
\hline 4 & 39 & 69 & Yes & 4 & 57 & 46 & no \\
\hline 5 & 29 & 96 & Yes & 5 & 27 & 30 & no \\
\hline 6 & 36 & 87 & Yes & 6 & 52 & 17 & no \\
\hline 7 & 45 & 92 & Yes & 7 & 35 & 45 & no \\
\hline 8 & 49 & 61 & No & 8 & 20 & 23 & no \\
\hline 9 & 61 & 73 & Yes & 9 & 40 & 53 & no \\
\hline 10 & 36 & 52 & No & & & & \\
\hline 11 & 41 & 55 & No & & & & \\
\hline \multicolumn{3}{|c|}{ Successful Treatment } & $63,7 \%$ & \multicolumn{3}{|c|}{ Successful Treatment } & $22,3 \%$ \\
\hline
\end{tabular}

CMS, indicates Constant and Murley Score; ESWT, extracorporeal shock wave therapy.

pain, $96.7 \%$ for the ADL, $99.1 \%$ for the ROM and $99.3 \%$ for the total score to detect the observed differences.

A telephone recall of the ESWT patients has been carried out nine years after treatment and we were able to collect data on 10 out of 11 individuals. No patient progressed to surgical intervention and two patients showed a recurrence of shoulder pain 3 and 4 years after ESWT, respectively. These patients were successfully treated with a second ESWT (1) and medication for pain with a regimen of scapulothoracic and glenohumeral range of motion and strengthening exercise (1). Nine years after ESWT all the patients available were satisfied with the treatment received and would have repeated the same therapy again.

\section{Discussion}

Thousands of ESWT for NCST are currently performed in Europe [12], even if the available evidence does not support the use of this technique with this indication [10]. Because of the small number of studies on this topic and the few application protocols tested up to now [11-13], we re-evaluated the efficacy of low energy ESWT for NCST using a new protocol. Indeed, it has been clearly demonstrated that different protocols considerably modify the success rate of ESWT [22].

For the first time, we have demonstrated that patients suffering from NCST may benefit from ESWT. Our findings showed a significant CMS improvement in the ESWT but not in the control group six and twelve weeks after treatment. Furthermore, significant CMS differences between the groups at follow-up were also noted. The ESWT was found to be safe and well tolerated by the patients.

The best evidence for new treatments usually comes from randomized, placebo-controlled, double-blind studies and our work tried to provide compelling evidence that ESWT is effective in NCST. Our protocol included random sequence generation, allocation concealment, and blinding. A great effort was made to mask the real ESWT in order to eliminate subjective bias on the part of both experimental subjects and the experimenters. Indeed, the ESWT masking appeared less than optimal in previous similar studies [11,13]. Because the minimum effect size of the CMS is not known [23], we considered a clinically significant response a 30-point increase in the CMS [11] which is considerably higher than the values chosen by others to evaluate ESWT [22,23]. However, it should be noted that the 30-point difference it's an arbitrary cut-off, not derived from research evidence. Interestingly, the study achieved a $100 \%$ rate of follow-up of patients, notwithstanding the presence of the placebo group.

Some limitations of the present investigation should also be acknowledged. The small sample size may have increased the risk of an underpowered randomized controlled trial. However, the differences in the CMS scores both within the ESWT group and between treatment groups at final follow-up were highly significant and the power analysis supported these findings, despite the small number of patients per group. Studies are considered to be adequately powered when there is about an $80 \%$ probability the study would show a treatment effect if it is present [24].

The short-term follow-up may have limited the generalizability of our study, even if the same follow-up interval was used previously in similar ESWT trials $[11,23,25]$. Notably, the short follow-up was useful to define the direct effects of ESWT on the clinical course of the condition and on the morphology of the supraspinatus tendon. Indeed, with a longer follow-up there might have been confusion between the effects of the treatment 
and spontaneous changes. A further restriction to increase the length of follow-up was the consideration that it is ethically and psychologically difficult to obtain informed consent to enter a study from patients presenting with chronic pain. The longer the duration of the study, the fewer are the individuals that would accept the possibility of receiving a sham treatment while suffering pain. Moreover, it should be noted that alternatives therapies are available to treat supraspinatus tendinopathy [3], and when treatments for a disorder already exist, it could be argued that it is unethical to create a placebo group that will receive no treatment at all. A different study design should be proposed to evaluate ESWT over a longer period.

The demonstration of ESWT efficacy in the short-term period is still a valuable finding of this investigation. Indeed, previous studies showed satisfactory outcomes in the short-term after other conservative therapies such as physical therapy [26] or subacromial cortisone injection [27-29]. However, we showed an higher improvement of CMS in comparison to the values reported by others treating the supraspinatus tendinopathy with ultrasounds or rehabilitation program with the same follow-up [26]. As for the corticosteroids, there is reasonably strong evidence that cortisone injection causes deleterious effects on the tendon and the outcomes deteriorates over time [30]. Indeed, the continued use of a local corticosteroid is discouraged [31]. On the contrary, no detrimental effects of ESWT for shoulder pain in the long-term period have been reported [32,33] and this treatment could eventually be repeated in case of recurrence of symptoms.

Our data are in keeping with the results of a recent study reporting significant increase in function and reduction of pain after low or high-energy ESWT in patients with NCST [12]. But our findings do not agree with the only two existing randomized, controlled studies that analyzed the efficacy of ESWT in NCST $[11,13]$. Indeed, Schmitt and colleagues reported significant CMS improvements both in low energy ESWT and in the placebo group three months after treatment, but no difference in CMS between the groups was noted [11], therefore shock waves were not recommended for NCST. However, in this study the method for administration of local anaesthetic involved use of a large bolus in the subacromial region (i.e. $10 \mathrm{cc}$ of mepivacaine) and certain dosages of local anaesthetic are considered to be therapeutic [27]. Further weakness in the sham design and the method of assessment of the supraspinatus tendon with either MRI or ultrasounds must be considered. The trial by Speed [13] analyzed medium-energy ESWT in comparison with a placebo treatment for non-calcific tendinopathy of the rotator cuff, and confirmed the findings of Schmitt three months after the completion of therapies. However, some weakness appears also in this study due to the sham design. In the placebo group, the treatment head was deflated and contact with the skin was avoided, and no local anaesthesia was used. Since shockwaves may cause pain and discomfort, the ESWT masking here is less than optimal. Notwithstanding the limitations of these studies, any comparison with our findings is difficult because of the several variables that define the application parameters of ESWT. The shock wave generator, the number of impulses, the focusing of the shockwave with respect to the tendon insertion, the number and the interval between each treatment session, all are important factors that have to be carefully considered [6]. It is possible that different treatment regimens may be more effective than others [22] and, to our knowledge, the treatment protocol we used has not been utilized previously in a similar clinical setting.

Notably, to overcome at least in part the limitation of a short-term follow-up we performed a recall of patients nine years after treatments and an high satisfaction rate with treatment received together with a low recurrence of shoulder pain was noted.

We reported a successful treatment in $22 \%$ of our patients in the placebo group. This finding could be explained by the placebo effect rather than by the injection of a local anesthetic used to mask the treatment. Indeed, it is unlikely that a small dosage of local anesthetic into the subcutaneous fat of the shoulder would have a therapeutic effect. In fact, it was previously demonstrated that only higher dosages of this drug injected above the subacromial space are effective in the treatment of chronic rotator cuff tendinopathy [27]. It should be noted that the regression to the mean due to the spontaneous improvement or fluctuations in symptoms can lead to a false impression of the placebo effect [34].

One controlled prospective randomized trial on ESWT for calcifying tendinopathy of the rotator cuff has demonstrated that focusing the shock waves on the calcified area rather than on the insertion of the supraspinatus tendon is more effective [35], but no data are available regarding the best area to focus the shock waves in NCST. We focused the shock waves at an area one $\mathrm{cm}$ proximal to the insertion of the tendon in the bone where areas of avascularity have been described [36-38]. It has still not been determined whether vascular changes occur or are associated with rotator cuff pathology [39], however, experimental studies have demonstrated that shockwaves improve the blood supply to the tendon tissue throughout a neovascularization process [40] and low energy ESWT modulates the synthesis of nitric oxide $[41,42]$, a molecule that plays a critical role in the regulation of vascular tone, angiogenesis [42], and in the degeneration of the tendon [43-45]. Recently, it has been suggested that shock waves behave 
fairly differently according to the clinical phase of the disease, even reducing the pathological angiogenesis associated with rotator cuff disease [46]. Further therapeutic mechanisms of ESWT in the treatment of tendinopathies have been hypothesized. ESWT have been shown to promote healing of tendinopathies by inducing TGF-beta1 and IGF-I [47]. However, the therapeutic mechanism of shock waves in the treatment of supraspinatus tendinopathy is still uncertain.

\section{Conclusion}

ESWT was found to be safe and well-tolerated and, for the first time, it was demonstrated that patients suffering from NCST may benefit from low energy shock waves, at least in the short-term. The extracorporeal shock wave application protocol is likely to play a key-role in the successful treatment of NCST. Future investigations should be undertaken on the long-term effects of this technique in NCST.

\section{Competing interests}

This study was supported, in part, by Storz Medical AG, Tagerwilen, Switzerland. The company put placebo shock wave equipment at our disposal but had no control over the data analysis and interpretation, the decision to publish, or the content of this article. The authors declare that they have no competing interests.

\section{Acknowledgements}

We are grateful to Francesca Condino, Ph.D for statistical advice

\section{Author details}

${ }^{1}$ Department of Orthopaedic and Trauma Surgery, Magna Græcia University, V.le Europa88100, Catanzaro, Italy. Extracorporeal Shock Wave Research Unit, Policlinico G.B. Rossi, Largo LA Scuro 1037134, Verona, Italy.

\section{Authors' contributions}

OG and EA, as principal investigators, conceived of this study and acquired the data and so had full access to all of the data in the study. DAR performed the statistical analyses. OG and DAR take responsibility for the accuracy of the data analyses, have interpreted the data and have written the manuscript. GG has made a critical revision of the manuscript for important intellectual content. All authors have read and approved the final manuscript.

Received: 13 October 2011 Accepted: 6 June 2012

Published: 6 June 2012

\section{References}

1. Chard MD, Sattelle LM, Hazleman BL: The long-term outcome of rotator cuff tendinitis - a review study. Br J Rheumatol 1988, 27:385-389.

2. Milgrom C, Schaffler M, Gilbert S, van Holsbeeck M: Rotator-cuff changes in asymptomatic adults. The effect of age, hand dominance and gender. J Bone Joint Surg Br 1995, 77:296-298.

3. Green S, Buchbinder R, Glazier R, Forbes A: Systematic review of randomized controlled trials of interventions for painful shoulder: selection criteria, outcome assessment, and efficacy. BMJ 1998, 316:354-360.

4. Rompe JD, Kirkpatrick CJ, Kullmer K, Schwitalle M, Krischek O: Dose-related effect of shock wave on rabbit tendo Achillis. A sonographic and histological study. J Bone Joint Surg Br 1998, 80:546-552.

5. Andres BM, Murrell GA: Treatment of tendinopathy: what works, what does not, and what is on the horizon. Clin Orthop Relat Res 2008, 466:1539-1554.

6. Sems A, Dimeff R, lannotti JP: Extracorporeal Shock wave therapy in the treatment of chronic tendinopathies. J Am Acad Orthop Surg 2006, 14:195-204.
7. Rompe JD, Schoellner C, Nafe B: Evaluation of low-energy extracorporeal shock-wave application for treatment of chronic plantar fasciitis. J Bone Joint Surg Am 2002, 84:335-341.

8. Ko JY, Chen HS, Chen LM: Treatment of lateral epicondylitis of the elbow with shock waves. Clin Orthop Relat Res 2001, 387:60-67.

9. Russo S, de Durante C, Gigliotti $S$, Galasso O: Shock wave management of footballer's tendinopathies. J Sports Traumatol Rel Res 1999, 21:84-88.

10. Huisstede BM, Gebremariam L, van der Sande R, Hay EM, Koes BW: Evidence for effectiveness of Extracorporal Shock-Wave Therapy (ESWT) to treat calcific and non-calcificrotator cuff tendinosis - A systematic review. Man Ther 2011, 30:1-15.

11. Schmitt J, Haake M, Tosch A, Hildebrand R, Deike B, Griss P: Low-energy extracorporeal shock-wave treatment (ESWT) for tendinitis of the supraspinatus. A prospective, randomised study. J Bone Joint Surg Br 2001, 83:873-876.

12. Schofer MD, Hinrich F, Peterlein CD, Arendt M, Schmitt J: High- versus low-energy extracorporeal shock wave therapy of rotator cuff tendinopathy: a prospective, randomised, controlled study. Acta Orthop Belg 2009, 75:452-458.

13. Speed CA, Richards C, Nichols D, Burnat S, Wies JT: Extracorporeal shock-wave therapy for tendonitis of the rotator cuff. A double-blind, randomised, controlled trial. J Bone Joint Surg Br 2002, 84:509-512.

14. Jobe FW, Jobe CM: Painful athletic injuries of the shoulder. Clin Orthop Relat Res 1983, 173:117-124.

15. Itoi E, Kido T, Sano A, Urayama M, Sato K: Which is more useful, the "full can test" or the "empty can test", in detecting the torn supraspinatus tendon?. Am J Sports Med 1999, 27:65-68.

16. Constant CR: An evaluation of the Constant-Murley shoulder assessment. J Bone Joint Surg Br 1997, 79:695-696.

17. Constant CR, Murley AH: A clinical method of functional assessment of the shoulder. Clin Orthop Relat Res 1987, 214:160-164.

18. Conboy VB, Morris RW, Kiss J, Carr AJ: An evaluation of the Constant-Murley shoulder assessment. J Bone Joint Surg Br 1996, 78:229-232.

19. Katolik LI, Romeo AA, Cole BJ, Verma NN, Hayden JK, Bach BR: Normalization of the Constant score. J Shoulder Elbow Surg 2005, 14:279-285.

20. Spielmann AL, Forster BB, Kokan P, Hawkins RH, Janzen DL: Shoulder after rotator cuff repair: MR imaging findings in asymptomatic individuals-initial experience. Radiology 1999, 213:705-708.

21. Maman E, Harris C, White L, Tomlinson G, Shashank M, Boynton E: Outcome of Nonoperative Treatment of Symptomatic Rotator Cuff Tears Monitored by Magnetic Resonance Imaging. J Bone Joint Surg Am 2009, 91:1898-1906.

22. Gerdesmeyer L, Wagenpfeil S, Haake M, Maier M, Loew M, Wörtler K, Lampe R, Seil R, Handle G, Gassel S, Rompe JD: Extracorporeal shock wave therapy for the treatment of chronic calcifying tendonitis of the rotator cuff: a randomized controlled trial. JAMA 2003, 290:2573-2580.

23. Albert JD, Meadeb J, Guggenbuhl P, Marin F, Benkalfate T, Thomazeau H, Chalès G: High-energy extracorporeal shock-wave therapy for calcifying tendinitis of the rotator cuff. J Bone Joint Surg Br 2007, 89:335-341.

24. Keen $\mathrm{HI}$, Pile K, Hill CL: The prevalence of underpowered randomized clinical trials in rheumatology. J Reumathol 2005, 32:2083-2088.

25. Sabeti-Aschraf M, Dorotka R, Goll A, Trieb K: Extracorporeal shock wave therapy in the treatment of calcific tendinitis of the rotator cuff. Am J Sports Medicine 2005, 33:1365-1368.

26. Giombini A, Di Cesare A, Safran MR, Ciatti R, Maffulli N: Short-term effectiveness of hyperthermia for supraspinatus tendinopathy in athletes: a short-term randomized controlled study. Am J Sports Med 2006, 34:1247-1253.

27. Alvarez CM, Litchfield R, Jackowski D, Griffin S, Kirkley A: A prospective, double-blind, randomized clinical trial comparing subacromial injection of betamethasone and xylocaine to xylocaine alone in chronic rotator cuff tendinosis. Am J Sports Med 2005, 33:255-262.

28. Adebajo AO, Nash P, Hazleman BL: A prospective double blind dummy placebo controlled study comparing triamcinolone hexacetonide injection with oral diclofenac $50 \mathrm{mg}$ TDS in patients with rotator cuff tendinitis. J Rheumatol 1990, 17:1207-1210.

29. Petri M, Dobrow R, Neiman R, Whiting-O'Keefe Q, Seaman WE: Randomized, double-blind, placebo-controlled study of the treatment of the painful shoulder. Arthritis Rheum 1987, 30:1040-1045.

30. Wilson JJ, Best TM: Common overuse tendon problems: a review and recommendations for treatment. Am Fam Physician 2005, 72:811-818. 
31. Coombes BK, Bisset L, Vicenzino B: Efficacy and safety of corticosteroid injections and other injections for management of tendinopathy: a systematic review of randomised controlled trials. Lancet 2010, 376:1751-1767.

32. Daecke W, Kusnierczak D, Loew M: Long-term effects of extracorporeal shockwave therapy in chronic calcific tendinitis of the shoulder. J Shoulder Elbow Surg 2002, 11:476-480.

33. Wang CJ, Yang KD, Wang FS, Chen HH, Wang JW: Shock wave therapy for calcific tendinitis of the shoulder: a prospective clinical study with two-year follow up. Am J Sports Med 2003, 31:425-430.

34. Kienle GS, Kiene H: The powerful placebo effect: fact or fiction?. I Clin Epidemiol 1997, 50:1311-1318.

35. Haake M, Deike B, Thon A, Schmitt J: Exact focusing of extracorporeal shock wave therapy for calcifying tendinopathy. Clin Orthop Relat Res 2002, 397:323-331.

36. Lewis JS: Rotator cuff tendinopathy. Br J Sports Med 2009, 43:236-241

37. Benson RT, McDonnell SM, Knowles HJ, Rees JL, Carr AJ, Hulley PA: Tendinopathy and tears of the rotator cuff are associated with hypoxia and apoptosis. J Bone Joint Surg Br 2010, 92:448-453.

38. Loehr JF, Uhthoff HK: The microvascular pattern of the supraspinatus tendon. Clin Orthop Relat Res 1990, 254:35-38.

39. Rothman RH, Parke WW: The vascular anatomy of the rotator cuff. Clin Orthop Relat Res 1965, 41:176-186.

40. Wang CJ, Wang FS, Yang KD, Weng LH, Hsu CC, Huang CS, Yang LC: Shock wave therapy induces neovascularization at the tendon-bone junction. A study in rabbits. J Orthop Res 2003, 21:689-984.

41. Gotte G, Amelio E, Russo S, Marlinghaus E, Musci G, Suzuki H: Short-time non-enzymatic nitric oxide synthesis from L-arginine and hydrogen peroxide induced by shock waves treatment. FEBS Lett 2002, 520:153-155.

42. Mariotto S, de Prati AC, Cavalieri E, Amelio E, Marlinghaus E, Suzuki H: Extracorporeal shock wave therapy in inflammatory diseases: molecular mechanism that triggers anti-inflammatory action. Extracorporeal shock wave therapy in inflammatory diseases: molecular mechanism that triggers anti-inflammatory action. Curr Med Chem 2009, 16:2366-2372.

43. Murrell GA: Oxygen free radicals and tendon healing. J Shoulder Elbow Surg 2007, 16:208-214.

44. Szomor ZL, Appleyard RC, Murrell GA: Overexpression of nitric oxide synthases in tendon overuse. J Orthop Res 2006, 24:80-86.

45. Xia W, Szomor Z, Wang Y, Murrel GA: Nitric oxide enhances collagen synthesis in cultured human tendon cells. J Orthop Res 2006, 24:159-172.

46. Notarnicola A, Moretti L, Tafuri S, Forcignanò M, Pesce V, Moretti B: Reduced local perfusion after shock wave treatment of rotator cuff tendinopathy. Ultrasound Med Biol 2011, 37:417-425.

47. Chen YJ, Wang CJ, Yang KD, Kou YR, Huang HC, Huang YT, Sun YC, Wang FS: Extracorporeal shock waves promote healing of collagenase-induced Achilles tendinitis and increase TGF-beta1 and IGF-I expression. J Orthop Res 2004, 22:854-861.

doi:10.1186/1471-2474-13-86

Cite this article as: Galasso et al:: Short-term outcomes of extracorporeal shock wave therapy for the treatment of chronic non-calcific tendinopathy of the supraspinatus: a double-blind, randomized, placebo-controlled trial. BMC Musculoskeletal Disorders 2012 13:86.

\section{Submit your next manuscript to BioMed Central and take full advantage of:}

- Convenient online submission

- Thorough peer review

- No space constraints or color figure charges

- Immediate publication on acceptance

- Inclusion in PubMed, CAS, Scopus and Google Scholar

- Research which is freely available for redistribution 